\title{
For Esophageal Cancer, Behind Every Successful Man...
}

\author{
Andrew T. Arndt, MD \\ Rush University Medical Center, Chicago, IL
}

The interplay between cancer diagnosis and mental well-being has long been appreciated; cancer patients have higher rates of depression and anxiety than the general population, and cancer patients with those diagnoses have worse outcomes than cancer patients without depression and anxiety. ${ }^{1}$ Additionally, the importance of social networks-particularly comprising close relatives-in cancer patients has been demonstrated as well, with social isolation being a risk factor for higher mortality rates after breast cancer diagnosis. ${ }^{2}$ In this issue of the Annals of Surgical Oncology, Yoshida and colleagues present a novel study evaluating the impact of not just a social network in general but rather a specific "key person" on esophageal cancer outcomes in their original manuscript titled "Wives as key persons positively impact prognosis for male patients undergoing esophagectomy for esophageal cancer: a retrospective study from a single Japanese institute." 3

This study retrospectively evaluated 504 patients who underwent three-incision esophagectomy for cancer between June 2005 and June 2018 at Kumamoto University Hospital and analyzed the relationship between patientidentified key person and long-term outcomes after surgery. The key finding from the study is that "the presence of the wife as the key person was significantly associated with better survival outcomes in male patients." 3 Interestingly, the conclusion very specifically applies to male cancer patients with wives as key persons: neither the presence of a husband for female patients nor the identification of a female in general as a key person impacted outcomes.

(C) Society of Surgical Oncology 2020

First Received: 9 March 2020;

Published Online: 30 March 2020

A. T. Arndt, MD

e-mail: Andrew_t_arndt@ rush.edu
Before we as a surgical community start prescribing marriage for every male patient with cancer, it is worth noting the specifics of the study that limit its immediate widespread applicability. The study by design included only operative esophageal cancer patients. Furthermore, the majority of diagnoses among included patients were squamous cell carcinoma (93\%), whereas the dominant type in Japan is not the most common histology in the United States nor other Western countries. It has long been known that esophageal adenocarcinoma and squamous cell carcinoma behave quite differently, with different etiology, epidemiology, and prognosis. ${ }^{4}$ Also limiting the study is that it is from a single institution and is retrospective in nature. Finally, the authors note that while not reaching significance, there were several differences in baseline characteristics between male patients with wives and those without wives.

Beyond the above limitations inherent to the methods, there are other analyses that would be interesting to run on this cohort of patients that may further shed light on what specific factors are important in a key person. While the authors compare wife to non-wife key person in male patients as well as female to non-female key person in all patients, they do not specifically compare wife to non-wife female key person in male patients. Also, while they note that all key person wives were living with the patients, they do not comment on the living situation of the other key persons studied.

Nevertheless, the truly intriguing aspect of this article is not that a very specific subset of male Japanese esophageal cancer patients benefited from having a wife but rather that there are in general certain qualities of key persons that can portend improved survival after a cancer diagnosis. The paper should challenge us to ask what it was about the key persons and their relationship with the included patients that was beneficial. 
The authors note that in Japanese society during the time period of this study, traditional values and roles in marriage were present, with Japanese wives typically working in domestic roles rather than outside the home. Such a traditional setup would mean that most Japanese wives were routinely present when their husbands were home (with the reverse not necessarily true owing to the males' role in the workplace), likely offering constant companionship and support; it is possible that the reliable daily presence of one's chosen partner has a favorable impact on mental and emotional well-being. Such traditional spousal roles also would mean that wives were primarily responsible for ensuring good nutrition for the family, whereas males in the study without wives may have lacked this domestic support.

Another interesting finding from the paper was that patients without a wife had a trend toward diagnosis at a more advanced clinical stage. This is concordant with the authors' contention that Japanese wives encourage healthy behaviors in their husbands and also help them keep medical appointments and manage comorbidities. Also in line with this claim is the fact that among males with recurrence, presence of a wife improved survival (though not reaching significance).

Ultimately, this thought-provoking manuscript reiterates the importance of a strong support system in patients with cancer. While the conclusions of this particular study apply to a very specific population, the broader theme is the importance of having a close advocate and motivator when dealing with a cancer diagnosis. Future work in this field will surely expand this concept to other cancer diagnoses that impact different populations and will likely help to pinpoint what specific qualities are most valuable in a key person.

DISCLOSURE The author declares no conflicts of interest.

\section{REFERENCES}

1. Pitman A, Suleman S, Hyde N, Hodgkiss A. Depression and anxiety in patients with cancer. BMJ. 2018;361:k1415.

2. Kroenke CH, Kubzansky LD, Schernhammer ES, et al. Social networks, social support, and survival after breast cancer diagnosis. J Clin Oncol. 2006;24:1105-11.

3. Yoshida N, Adachi Y, Morinaga T, et al. Wives as key persons positively impacting prognosis for male patients undergoing esophagectomy for esophageal cancer: a retrospective study from a single Japanese institute. Ann Surg Oncol. 2020. https://doi.org/ 10.1245/s10434-020-08378-w.

4. Lin MQ, Li YP, Wu SG, et al. Differences in esophageal cancer patient characteristics and survival between Chinese and Caucasian patients in the SEER database. Oncol Targets Ther. 2016;9:6435-44.

Publisher's Note Springer Nature remains neutral with regard to jurisdictional claims in published maps and institutional affiliations. 